\title{
JURISPRUDENCIA CONSTITUCIONAL EN MATERIA DE CONTROL DE LEGALIDAD (TOMA DE RAZÓN Y POTESTAD DICTAMINANTE) DE LA CONTRALORÍA GENERAL DE LA REPÚBLICA*
}

\author{
ENRIQUE NAVARRO BELTRÁN**
}

\section{1) TOMA DE RAZÓN Y RECURSO DE PROTECCIÓN ${ }^{1}$}

\section{1.) FUNDAMENTOS CONSTITUCIONALES DE LA TOMA DE RAZÓN}

De acuerdo a lo dispuesto en el actual artículo 98 de la Constitución Política de la República (en adelante "CPR"), la Contraloría General de la República (en adelante "CGR") es un organismo autónomo que ejerce el control de legalidad de los actos de la Administración, fiscaliza el egreso y la inversión de los fondos del Fisco, de las municipalidades y de los demás organismos y servicios que determinen las leyes; examina y juzga las cuentas de las personas que tengan a su cargo bienes de esas entidades; lleva la contabilidad de la general de la Nación y desempeña las demás funciones que le encomiende su ley orgánica constitucional ${ }^{2}$. Se trata de

\footnotetext{
* Abreviaturas usadas:

C.A.: $\quad$ Corte de Apelaciones

CGR: Contraloría General de la República

C.S.: $\quad$ Corte Suprema

GJ: $\quad$ Revista Gaceta Jurídica

RDJ: $\quad$ Revista de Derecho y Jurisprudencia

RDP: $\quad$ Revista de Derecho Público, U. de Chile

RDUFT: Revista de Derecho, U. Finis Terrae

TC: $\quad$ Tribunal Constitucional

TD: $\quad$ Revista Temas de Derecho, U. Gabriela Mistral

** Abogado. Licenciado en Ciencias Jurídicas y Sociales (U. de Chile). Profesor Titular de Derecho Constitucional de la U. de Chile, siendo Director del Departamento de Derecho Público, desde 2003. Profesor Titular de Derecho Constitucional de la U. Finis Terrae, donde es Director de Investigación y de la Revista de Derecho de la UFT. Ha sido Director de Estudio de la Corte Suprema (2002-2006) y Ministro del Tribunal Constitucional (2006-2012).

1 Una primera versión de este artículo -actualizada a 2006- se publicó en RDUFT 11 (2007). En dicha publicación -en homenaje a los 80 de su establecimiento- se incluyen diversas investigaciones acerca de la Contraloría General de la República. En 1977, el Departamento de Derecho Público de la U. de Chile preparó una obra conmemorativa de los 50 años. Posteriormente, el año 2002, la Contraloría General de la República editó un libro alusivo a los 75 años. A fines de este ańo está previsto una obra similar, con motivo de los 85 años.

2 Las atribuciones y funciones de dicho órgano de control pueden encontrarse tanto en la la ley No 10.336, como en otros ordenamientos legales, siendo solo imperativo para la validez normativa la jerarquía orgánica constitucional de las mismas. (TRIBunal ConstitucioNAL, 11.12.2007, Rol No 796/2007, consid. 8º. En el mismo sentido, TC, 18.1.1990, Rol
} 
un órgano, establecido en $1927^{3}$-aunque con antecedentes históricos en instituciones hispánicas ${ }^{4}-$ y constitucionalizado en $1943^{5}$, que goza de autonomía constitucional, misma que tiene una dimensión organizativa, institucional y normativa, según lo ha señalado el Tribunal Constitución (en adelante "TC")

Ahora bien, el artículo 98 de la Constitución Política de la República otorga a la Contraloría General de la República la facultad de ejercer "el control de legalidad de los actos de administración. Por su parte, el artículo 99 de la misma Ley Fundamental indica que "en el ejercicio de la función de control de legalidad, el Contralor General tomará razón de los decretos y resoluciones que, en conformidad a la ley, deben tramitarse por la Contraloría o representará la ilegalidad de que puedan adolecer; pero deberá darles curso cuando, a pesar de su representación el Presidente de la República insista con la firma de todos sus Ministros, caso en el cual deberá enviar copias de los respectivos decretos a la Cámara de Diputados". Obviamente, no procede la insistencia en caso que la representación tenga lugar respecto de un decreto o resolución que se estime contrario a la Constitución Política, en cuya situación solo se prevé la facultad del Presidente de la República de recurrir al Tribunal Constitucional para que resuelva la controversia, en los términos que establecen los artículos 99 y 93 No 9 de Carta Política.

Por su lado, el artículo 10 de la Ley 10.336, que fija el texto refundido de la ley de organización y atribuciones de la Contraloría General de la República, señala que el Contralor General de la República tiene competencia para pronunciarse sobre la constitucionalidad y legalidad de los Decretos y Resoluciones, sin perjuicio de la facultad para eximir del trámite de toma de razón a "los decretos o resoluciones que concedan licencias, feriados, y permisos con goce de sueldo, o que se refieran a otras materias que

91/1989). En tal sentido, el TC ha señalado que es propio de la ley orgánica constitucional lo relativo a la normativa sobre: a) aplicación inmediata de decretos (TC, 11.1.1991, Rol 117/91, c. 4; TC, 12.2.1992, Rol 142/92, c. 5; TC, 13.4.1993, Rol No 168/93, c. 3); b) impresión de títulos representativos de deuda pública (TC, 17.09.2003, Rol 390/2003, c. 6); c) nombramiento de funcionarios y reclamo por vicios (TC, 12.09.1989, Rol 79/89, c. 10); d) aplicación de facultades fiscalizadoras de la CGR a sector portuario (TC, 1.12.1997, Rol 267/97, c. 5), a corporaciones y fundaciones constituidas por gobiernos regionales (TC, 14.06.2005, Rol 443, c. 10) y a consejo privado (TC, 18.06.2003, Rol 377/03, c. 10); e) procedimiento de rendición de cuentas de gastos reservados de los ministerios (TC, 29.01.2003, Rol 366/03, c. 10) y f) efectos de decretos o resoluciones desde el ingreso a la CGR (TC, 29.07.2003, Rol 381/03, c. 7). Una visión sistemática de la jurisprudencia en Navarro, Enrique y Carmona, Carlos (2011), "Repertorio de Jurisprudencia del Tribunal Constitucional 1981-2011", Ed. Tribunal Constitucional, Santiago, 600 pp.

3 Decreto con Fuerza de ley $\mathrm{N}^{\circ} 400$ bis, de 26 de marzo de 1927

4 Pinto, Sonia, Méndez, Luz María y Vergara, Sergio (1977), “Antecedentes históricos de la Contraloría General de la República”, Ed. Contraloría General de la República, Santiago, 456 pp.

Reforma constitucional aprobada por Ley $\mathrm{N}^{\circ} 7.727$, de 1943

6 TC, 10.07.2008, Rol 1051/2008, c. 37 
no considere esenciales" 7 . En tal sentido, la ley 19.880, sobre bases de los procedimientos administrativos, reitera en su artículo $1^{\circ}$ que "la toma de razón de los actos de la Administración del Estado se regirán por lo dispuesto en la Constitución y en la Ley Orgánica Constitucional de la Contraloría General de la República".

Se trata de un amplio control, tanto constitucional como de legalidad, según lo ha destacado tradicionalmente la doctrina ${ }^{8}$.

De este modo, en palabras de la judicatura, el control jurídico que efectúa la CGR se lleva a efecto "por medio del pronunciamiento que debe hacer sobre la constitucionalidad y legalidad de los decretos supremos y resoluciones de los jefes de servicios, a través de la emisión de dictámenes jurídicos que en materia administrativa deben observar las reparticiones públicas que los soliciten y mediante la fiscalización en el cumplimiento de las disposiciones del Estatuto Administrativo"'.

En todo caso, debe señalarse que el Tribunal Constitucional ha reiterado, en resolución de 15 de julio de 2002, la amplia facultad del órgano contralor para representar la inconstitucionalidad e ilegalidad de los actos de la administración y la improcedencia del decreto de insistencia si se ha objetado la constitucionalidad del mismo. En efecto, la Magistratura Constitucional declaró ajustado a la Constitución el precepto contenido en un proyecto que establecía la facultad del Presidente de la República de dar curso a los decretos supremos y resoluciones de Jefes de Servicio representados, cuando insistiera con la firma de todos sus ministros, en el entendido de que la insistencia del Presidente es improcedente para el caso en que la representación de Contraloría se motivara en la contrarie-

7 Ello se encuentra señalado nominativamente en la Resolución $N^{\circ} 1600$, dictada por la Contraloría General de la República, con fecha 30 de octubre de 2008.

8 De este modo, como lo ha indicado la doctrina, le corresponde a la Contraloría General de la República, revisar "mediante el examen, a través de la toma de razón, de la constitucionalidad y legalidad de los decretos supremos y resoluciones de los jefes de servicio (SILva Enrique, (1994), "Derecho Administrativo, El control público", Ed. Jurídica de Chile, Santiago, p. 171). En el mismo sentido, la Corte Suprema ha señalado que el trámite de toma de razón "involucra un pronunciamiento del organismo contralor acerca de la constitucionalidad y legalidad de un determinado decreto o resolución" (Corte Suprema, 29.01.2002, Rol 67/02). Por lo mismo, se ha señalado que "tanto la Constitución (art. 88) como la ley 10.336 (arts. 1 y 10), le asignan a la Contraloría la potestad para pronunciarse sobre la 'constitucionalidad y legalidad' de los actos de la administración (...) de donde aparece patente y claro -y sin limitaciones de ninguna especie- que debe velar por la observancia irrestricta de las normas siguientes: a) de la Constitución y b) de las leyes" (ARóstiCA, Iván (1991), "El trámite de toma de razón de los actos administrativos", RDP 49, p. 137). Así las cosas, sin toma de razón "no es posible cumplir ninguna decisión del administrador, no cabe su aplicación; es más, su ejecución, en el supuesto que se pretenda hacerlo, acarrea por ese solo hecho la pérdida del empleo del funcionario ejecutor". (SOTO, Eduardo (1977), "La toma de razón y el poder normativo de la Contraloría", en Libro Homenaje a la Contraloría General, Departamento de Derecho Público, Santiago de Chile, p. 174).

9 Corte de Apelaciones de Santiago, Rol 6552-2006, confirmado por la CS, Rol No 7702007. En el mismo sentido, CA de Santiago, Rol 5711-2006, confirmado por la CS, Rol No 2008-2007 
dad con la Constitución. Así, textualmente declaró "Que, sin embargo, atendida la amplitud de la norma en estudio, esto es, que el Contralor deberá darles curso a los respectivos decretos o resoluciones que represente cuando el Presidente de la República insista con la firma de todos sus ministros, sin efectuar distinción alguna sobre la causa de la representación, esta Magistratura estima necesario expresar que declarará la constitucionalidad del artículo 10, inciso primero, de la Ley $N^{\circ} 10.336$, y sus modificaciones, en el claro entendido que la insistencia del Jefe del Estado es improcedente en el caso que los decretos o resoluciones hayan sido representados por el Contralor por ser contrarios a la Constitución. Lo anterior se funda en lo prescrito en el articulo 88, inciso tercero, de la Carta Fundamental (...) Esta disposición armoniza y concuerda con la atribución que se le confiere al Tribunal Constitucional por el artículo 82, $N^{\circ} 6^{\circ}$, de la misma Carta (...)"'10.

En cuanto a la obligatoriedad del trámite de toma de razón, el TC ha expresado que "los actos administrativos explicados se hallan sometidos a controles diversos según su jerarquía. Asi, los decretos reglamentarios deben ser siempre revisados mediante el control preventivo denominado toma de razón, practicado por la Contraloría General de la República. En cambio, los simples decretos supremos, las resoluciones y las instrucciones pueden ser eximidos de ese trámite, con las exigencias de resguardo previstas en la ley, esto es, en el artículo 10 de la Ley Orgánica Constitucional de la Contraloría General de la República"1 1 . Todo lo anterior, por cierto, sin perjuicio de las facultades de otros órganos, particularmente jurisdiccionales ${ }^{12}$.

Por ello la jurisprudencia de nuestros tribunales superiores de justicia ha ratificado la circunstancia que "en nuestro sistema jurídico en virtud del principio jerárquico, el Decreto o el Reglamento debe subordinarse a la ley y esta a la Carta Fundamental"13, dado que "es un principio básico de derecho, reconocido por el articulo 7 de la Constitución el que los entes estatales no tienen más atribuciones que las que le fueron conferidas de manera expresa

\footnotetext{
TC, 15.07.2002, Rol 356/02

TC, 11.01.2007, Rol 591/06
}

Por eso se ha sentenciado que "si bien mediante el trámite de toma de razón establecido en el artículo 87 de la Carta Fundamental, la Contraloría General de la República analiza la legalidad y constitucionalidad de los actos de la administración, no es menos cierto que el ordenamiento jurídico ha previsto un conjunto de mecanismos encaminados a resguardar el principio de la supremacia constitucional, entre ellos la facultad del Tribunal Constitucional de declarar la inconstitucionalidad de un decreto promulgado y publicado (artículo 80 de la Constitución), o la facultad de los tribunales de declarar inconstitucional actos de autoridad a través de un recurso de protección (artículo 20 de la Constitución), o de la acción ordinaria de nulidad de derecho público (artículos $6^{\circ}$ y $7^{\circ}$ de la Constitución). Por lo demás, de acuerdo a estos últimos artículos, esta obliga a todos los poderes del Estado -entre ellos por cierto los tribunales de justicia-los cuales deben velar para que los actos de los particulares y de la autoridad administrativa se encuadren dentro del marco establecido en la Constitución Politica y en la ley" (C. A. de Santiago, 15.05.1996, Rol 4013/95, confirmado por la C. S., 19.06.1996, Rol No 2291/06). 
por la Constitución y las leyes dictadas en su conformidad"14. Se trata de una concreción del principio de supremacía constitucional ${ }^{15}$. Así, la Contraloría General de la República, en palabras del mismo ente, "es un organismo superior de control de la administración, dotado de autonomía y que, sobre la base del principio de juridicidad, está destinado a garantizar el cumplimiento del ordenamiento jurídico, la protección y debido uso del patrimonio público, la preservación y fortalecimiento de la probidad administrativa y la fidelidad $y$ transparencia de la información financiera"16.

\section{2.) PronunCiamientos del TC Respecto de la toma de RAZón}

El Tribunal Constitucional se ha pronunciado en diversas oportunidades en relación a la pretensión legislativa de restringir o limitar las facultades constitucionales de dicho órgano.

Así, frente a un proyecto de ley que restringía la fiscalización de un ente estatal exclusivamente al examen de cuentas de entradas y gastos, se entendió que ello importaba una limitación a las actividades y funciones de control y fiscalización que le competen. En efecto, se sostiene que ello vulneraría la Constitución "pues ha contemplado solamente una de las actividades y funciones que el constituyente de 1980 señaló como aquellas a ser cumplidas por Contraloria General de la República, omitiéndose entre otras la principal de ellas consistente en el ejercicio del control de la legalidad que efectúa el Contralor General a través de la "Toma de razón" de los decretos y resoluciones de los organismos y servicios que forman la administración del Estado", concluyendo que "de aceptarse el texto del artículo $1^{\circ}$ contenido en el proyecto de ley en examen, en lo referente a la actividad de fiscalización de la Contraloría General de la República, se estaría vulnerando también la Constitución, pues se estaría impidiendo o limitando aquellas funciones a que se refiere la parte final del inciso primero del artículo 87 cuando señala que la Contraloría desempeñará "las demás funciones que le encomienda la ley orgánica constitucional respectiva"17.

Del mismo modo, al establecerse en un proyecto de ley que un fondo público estaría sometido solo a la auditoría contable de la Contraloría

\footnotetext{
14 C. A. de Santiago, 4.05.1988, RDJ 85, sec. 5a., 1988, p. 168

15 Como consecuencia de dichos principios de supremacía constitucional y de legalidad, la doctrina nacional ha afirmado que "el constituyente exige que los preceptos de toda indole emanados o que emanen de cualquier autoridad, se atengan a las bases de organización, procedimiento y solemnidades que dispone la misma Ley Fundamental y al mismo tiempo, en armonía con su sustancia normativa, en la que se incluye la invocación a los valores en que ha de inspirarse las decisiones (...) la ley fundamental otorga facultades precisas destinadas a hacer efectiva la supremacía constitucional a determinados órganos, como la (...) Contraloría General de la República”. (Silva, Alejandro (1997) "Tratado de Derecho Constitucional", Ed. Jurídica de Chile, Santiago, Tomo IV, pp. 135 y 136).

16 CGR, Dictamen No 01556, de 25.10.2000

17 TC, 15.01 .1990 , Rol 92/90, c. 7 a 9
} 
General de la República, se precisó que ello "es sin perjuicio de las demás atribuciones que posee dicha Contraloría en relación con la fiscalización de los fondos públicos, de acuerdo con lo dispuesto por el artículo 87 de la Carta Fundamental"18.

En otro caso, en el que también se limitaba la facultad fiscalizadora respecto de la superintendencia de isapres exclusivamente al examen de cuentas de entradas y gastos, el Tribunal Constitucional declaró, en una sentencia interpretativa expresa que el precepto "se ajusta a lo dispuesto en el inciso primero del artículo 98 de la Ley Fundamental, en el entendido que no excluye el ejercicio del control de legalidad de los actos de la administración, en lo que fuere procedente, con sujeción a lo dispuesto en el inciso primero del artículo 99 de la misma Constitución Politica. Lo anterior, siguiendo el principio de buscar la interpretación de las normas que permita resolver, dentro de lo posible, su conformidad con la Constitución"19.

Más recientemente, respecto del proyecto de ley del Consejo para la Transparencia y, en cuanto a la circunstancia que este solo quedaría sujeto a la fiscalización de la Contraloría en lo que concierne a su personal y al examen y juzgamiento de sus cuentas, el TC lo declara ajustada a la Ley Fundamental "en el entendido de que esta limitación a las facultades que se confieren a la Contraloria General de la República, en la norma transcrita, deja a salvo el control amplio de legalidad que confiere a este órgano el artículo 98, inciso primero, de la Carta Fundamental, en lo que fuere procedente" 20.

El TC ha seńalado que -en todo caso- el acto que ha sido tomado razón goza de un suerte de presunción de legalidad y constitucionalidad, no siendo por tanto definitiva, dado ello puede ser revisada tanto ante el propio TC como ante los tribunales de justicia ${ }^{21}$.

\section{3.) REVISIÓN JUDICIAL DE LA FUNCIÓN CONTRALORA}

En esta materia se presentaron ya en la década de los noventa algunas acciones de protección vinculadas al ejercicio de la facultad de toma de razón del organismo contralor.

Así, se ha señalado que "la procedencia del recurso de protección en el caso de que se trata, es una consecuencia lógica de la amplitud con que está consagrado en el articulo 20 de la Carta Fundamental, que no excluye ni exceptúa de su aplicación a ninguna persona, autoridad política o administrativa u órgano del Estado, siendo, en consecuencia, el Contralor General de la República una autoridad susceptible de esta acción. Ello no importa alteración de su autonomía ni de su función de control previo de la legalidad de los

\footnotetext{
TC, 4.01.1994, Rol 178/93, c. 11

TC, 4.03.2008, Rol 1032/08, c. 17

TC, 10.07 .2008 , Rol 1051/08, c. 34

TC, 27.12.1990, Rol 116/90, c. 3 y 4
} 
actos administrativos, porque las finalidades de la actividad jurisdiccional de los Tribunales Superiores de Justicia en estos casos, son independientes de las funciones propias del organismo contralor y procedentes solo cuando se trata de actos $u$ omisiones arbitrarias o ilegales que quebranten garantías constitucionales a que se refiere el artículo 20 de la Constitución"22. La situación, como se sabe, incluso generó contiendas de competencias que resolvió el Senado el favor de la Contraloría General de la República ${ }^{23}$.

En otro fallo, dictado en la década de los noventa, se precisa que el artículo 20 de la Carta Fundamental le otorga amplias facultades a los tribunales de justicia, sin excluir al órgano contralor, haciendo presente que las resoluciones del Senado tuvieron un efecto particular, declarando arbitraria e ilegal la resolución en virtud de la cual se negó tomar razón de una resolución del Ministerio de Transporte que adjudicaba una propuesta ${ }^{24}$.

En tal sentido, cabe hacer presente una sentencia que señala la procedencia de la acción de protección respecto de las actuaciones de la Contraloría General de la República. Así, se sostiene que de acuerdo al artículo 20 del texto constitucional, le compete a los tribunales también conocer del recurso de protección y adoptar las medidas para restablecer el derecho que hubiese amagado o conculcado aún por la Contraloría General en el ejercicio del control de la legalidad de los actos de la Administración. La Corte en estos casos de excepción ha señalado que el recurso de protección era la única vía idónea para tal efecto ${ }^{25}$.

Así, se ha fundamentado "Que el tribunal que conoce el recurso de protección deducido en relación con un acto del Contralor se limita a pronunciarse sobre la ilegalidad o arbitrariedad imputada en la acción cautelar y sus efectos en el ejercicio legitimo de ciertos derechos garantizados por la Constitución Política. No sustituye a la autoridad o ente recurrido en el ejercicio de sus facultades propias ni pretende arrogarse estas potestades".

De modo que "entrar a conocer de este recurso no implica desconocer las atribuciones del Organismo Contralor, como se sostiene en el informe,

22 C. A. de Santiago, 16.12.1997, Rol No 4.327/07

23 Al respecto vid. RUFT 1, 1997. En tal sentido, señaló el Senado que “a) Que -como se ha expresado- sería procedente un recurso de protección fundado en la falta de competencia del Órgano Contralor cuando éste, actuando al margen de sus atribuciones, pretendiere ejercer una función que nuestro ordenamiento juridico no le entrega, pero no para impugnar la forma en que aquél ejerce su función de control de legalidad o el razonamiento que sirve de base a su decisión, como se pretende en este caso"; y "b) que de la demora en que pudiere haber incurrido el Contralor General, para cumplir con este trámite de toma de razón, podría servir de fundamento a un recurso de protección dirigido a solicitar que se le fije plazo para hacerlo, pero de ninguna manera para pedir, una vez evacuado el trámite que la decisión de la mencionada autoridad sea modificada o dejada sin efecto, como ocurre en el caso en análisis"

24 Sentencia de la C. A. de Santiago, 28.05.1996, Rol No 1.175, confirmada por la C. S., 12.08.1996, Rol No 2.254/96

25 C. A. de Santiago, 15.07.2000, Rol 4.786/99, acogido y confirmada por sentencia de la C.S., 10.08.2000 
sino resolver si en el ejercicio de la facultad de control de legalidad de un acto de la administración, se ha incurrido en arbitrariedades e ilegalidades que conculquen algunas de las garantias a que se refiere el artículo 20 de la Ley Suprema, unica vía constitucional idónea para hacerlo".

Posteriormente, en un fallo dictado el año 2004, se insiste que las facultades constitucionales y legales de la CGR referidas al control de la juridicidad de los actos administrativos no debe entrar en colisión con las potestades jurisdiccionales de los tribunales, "la que solo puede ser ejercida cuando la actuación del ente contralor se aparta de su función propia"26. Sin embargo, más reciente jurisprudencia ha precisado que "el trámite de toma de razón constituye una función de carácter constitucional que es de uso exclusivo y excluyente del Contralor General, razón por la cual no puede ser impugnada a través de un recurso de protección"27.

\section{2) POTESTAD DiCTAMINANTE Y RECURSO DE PROTECCION}

\section{1.) LA POTESTAD DiCTAMINANTE DE LA CONTRALORÍA}

La facultad de cualquier afectado por un acto ilegal dictado por un servicio público para solicitar dictamen ${ }^{28}$ a la Contraloría General de la República encuentra fundamento constitucional en el artículo $19 \mathrm{~N}^{\circ} 14$ que autoriza a cualquier persona a "presentar peticiones a la autoridad sobre cualquier asunto de interés público o privado, sin otra limitación que de la proceder en términos respetuosos y convenientes". En armonía con lo anterior, a nivel legal, el artículo 8 de la ley orgánica constitucional de bases generales de la administración del Estado $\mathrm{N}^{\circ} 18.575$, en su artículo $8^{\circ}$ indica que "los órganos de la administración del Estado actuarán por propia iniciativa en el cumplimiento de sus funciones o, a petición de parte cuando la ley lo exija expresamente o cuando se haga uso del derecho de petición o reclamo". Materializando la garantía constitucional aludida, el artículo $5^{\circ}$ de la Ley Orgánica de la Contraloría señala, dentro de las facultades del Contralor General de la República, la posibilidad de que este emita dictámenes "a petición de parte o de jefaturas de servicios o de otras autoridades".

26 C. A de Santiago, 16.03.2004, Rol No 578/04, confirmada por la C. S., 5.05.2004, Rol $1.112 / 04$

27 C.A. de Santiago, Rol No 2767/2006, confirmado por la C. S., Rol No 5057-2007

28 El dictamen es "un acto de consulta formulado por los Ministerios o Jefaturas de Servicios en materias de competencia de la Contraloria General o un acto de respuesta a peticiones de particulares o funcionarios que reclamen el reconocimiento de derechos que les sean desconocidos por la administración y siempre que las situaciones que los afecten importen una violación de normas cuyo cumplimiento corresponda fiscalizar al organismo contralor". (Aylwin, Patricio (1996), "Derecho Administrativo", Ed. Universidad Andrés Bello, Santiago, p. 320). 
Ciertamente, la potestad dictaminante tiene fundamento en la propia Carta Fundamental, al conferirle a la Contraloría el control de legalidad de los actos de la administración ${ }^{29}$. Especialmente relevancia adquiere en materia municipal dado que dichos actos están exentos de toma de razón ${ }^{30}$. Se trata de una materia que ha sido ampliamente analizada por la doctrina ${ }^{31}$.

Estos dictámenes son obligatorios para los funcionarios públicos afectados, según lo indica el artículo 9 de la Ley Orgánica aludida. Así, por ejemplo, se ha señalado por la judicatura en el ámbito municipal ${ }^{32}$.

29 La C. S. ha sentenciado por lo mismo "Que estas normas, con base constitucional en el artículo 98 de la Carta Fundamental, confieren a la Contraloría General de la República facultades para interpretar las normas y de este modo ejercer el control de legalidad que prevé dicho precepto" (CS, 13.10.2009, Rol 4533/09).

30 Por lo mismo, se ha expresado que "si bien las resoluciones municipales se encuentran exentas del trámite de toma de razón y solo están afectas a registro, por lo que los decretos alcaldicios relativos a personal rigen "in actum", esto es, desde la fecha de su dictación y posterior notificación al afectado, la exención de la toma de razón que beneficia a los actos municipales no significa que éstos queden al margen del control de legalidad, ya que el Órgano Contralor puede emitir dictámenes sobre todas las materias sujetas a su control, conforme lo reconocen los artículos 98 y 99 de la Constitución Política de la República, artículos 1, 5, 6 y 9 de la Ley $N^{\circ} 10.336$ y artículos 51 y 52 de la Ley $N^{\circ} 18.695$, sobre Municipalidades" (CS, 1.09.2010, Rol 5959/10).

31 Cabe recordar que el ex Contralor Arturo Aylwin ha expresado sobre esta facultad que: "El órgano contralor tiene amplias atribuciones para impartir instrucciones o emitir dictámenes a requerimiento de los ministros de Estado, jefes superiores de servicio u otras autoridades. También puede hacerlo a petición de funcionarios o de particulares cuando, habiéndole solicitado éstos a la administración activa, no se hubiere emitido pronunciamiento alguno o se haya denegado el derecho pretendido". (AyLwin, Arturo (2001), "Algunas reflexiones sobre la Contraloría General de la República", en 20 años de la Constitución Chilena (Ed. E. Navarro B), Universidad Finis Terrae, Santiago, p. 608. Precisamente por lo mismo, se ha sostenido que "otro medio de fiscalización que se reserva Contraloría es la emisión de dictámenes, al amparo de atribuciones generales que en tal sentido le acuerdan los artículos 6, 9 y 19 de su ley orgánica...". (ARóstiCA, Iván (1991), "El trámite de toma de razón de los actos administrativos”, RDP N49, p.159). Como consecuencia de lo seńalado, el ex Contralor General de la República don Enrique Silva Cimma, ha sostenido al efecto que el control de legalidad "puede ser previo o a posteriori. En el primer supuesto, se trata de que el acto sea controlado antes de su ejecución y, por lo tanto, de que no llegue a ejecutarse si es ilegal. En lo segundo, se aprueba o tacha el acto una vez ejercitado y, por lo tanto, en este último evento se procurará o su anulación o la reparación de los daños que el acto ilegal causó en la administración como a terceros, según corresponda". (Silva, Enrique (1994), "Derecho Administrativo Chileno y Comparado", Ed. Jurídica de Chile, Santiago, T. III, p. 46).

32 Vid. C.S., 10.12.2010, Rol 7890/10, en donde se expresa que "la Municipalidad recurrida se encuentra obligada a cumplir el Dictamen No 38.280 de la Contraloría General de la República en virtud de lo dispuesto en los artículos 98 de la Carta Fundamental y 10 y $6^{\circ}$ de la Ley $N^{\circ} 10.336$, en relación con los artículos 51 y 52 de la Ley $N^{o} 18.695^{\prime}$. Así lo ha precisado la doctrina, al expresar que el organismo contralor "realiza control jurídico mediante la emisión de dictámenes que, cuando inciden en las materias administrativas que especificamente señala el artículo $\sigma^{\circ}$ de su ley orgánica, constituyen la jurisprudencia administrativa y por ende, tienen carácter vinculante para la administración (Ley No10.336, artículo 5o, inciso 3o, y 19)" (Aylwin Patricio (1996), p. 172). Tal opinión es reafirmada por otro destacado autor, al hacer presente que "tales dictámenes vinculan a quienes los solicitan, y a quienes deban aplicarlos (art.9 y 6 y 17 y 19 LOCGR), y no solo a ellos sino también a quienes siendo particulares se relacionan con la administración, la cual se encuentra vinculada por aquella jurisprudencia contralora constituida por esos dictámenes". (Sото, Eduardo (1982), "El Recurso de Protección", Ed. Jurídica de Chile, Santiago, 1982, p.377). 
De este modo, el control jurídico de la CGR se lleva a efecto "por medio del pronunciamiento que debe hacer sobre la constitucionalidad y legalidad de los decretos supremos y resoluciones de los jefes de servicios, a través de la emisión de dictámenes jurídicos que, en materia administrativa, deben observar las reparticiones públicas que los soliciten, y mediante la fiscalización en el cumplimiento de las disposiciones del Estatuto Administrativo"33.

En lo tocante a las limitaciones respecto de la potestad dictaminante, el legislador ha previsto dos situaciones en las que no resulta procedente como son los asuntos litigiosos y aquellos que se encuentran sometidos al conocimiento de los tribunales de justicia. En tal sentido se ha señalado que el estudio de la legalidad de una resolución exenta de un servicio público y que daba inicio a un procedimiento fijación de tarifas "no es por su naturaleza, de carácter litigioso, esto es, de aquellos asuntos propensos a mover un litigio o pleito" 34 . Del mismo modo, tampoco se estima como sometida al conocimiento de los tribunales, desde que "no versan sobre ella las medidas cautelares prejudiciales "y "no se pidió tampoco declaración de nulidado ilegalidad ni se acreditó que existiera en tramitación demanda o recurso presentado ante tribunal alguno"35.

Por último, se ha resuelto en recursos de protección en que no ha sido parte la Contraloría General, pero se ha pretendido hacer valer la obligatoriedad de los dictámenes, que estos no tienen tal carácter para los tribunales y solo pueden ser considerados como antecedentes ilustrativos ${ }^{36}$.

\section{2.) IMPUGNACIÓN JUDICIAL DE LOS DICTÁMENES}

En general se ha estimado que los dictámenes pueden ser impugnados por la vía de recursos de protección. Así, la Corte Suprema ha confirmado una sentencia de Corte de la Apelaciones de Santiago recaída en una protección, en cuyo considerando séptimo dispone: "Que tampoco es efectivo que no puede recurrirse de protección en contra de un dictamen de la Contraloría, porque ésta los emite de acuerdo con sus facultades. En efecto, aunque, al emitir un dictamen, la Contraloría lo hace dentro de sus atribuciones y aun de sus obligaciones, en la forma no puede considerarse este acto arbitrario o ilegal, pero su contenido puede serlo y, al igual que una

C.A. de Santiago, 4.04.2007, Rol 5711/06, confirmado por C. S. Rol № 2008-07

C.A de Santiago, Rol No 8317-2005, confirmado por la C. S., Rol No 2199-2006

Ibíd.

C. A. Santiago, 19.05.1989, Rol 89/89. Tal recurso se declaró sin lugar, resolviendo en su considerando 50 "que los dictámenes de la Contraloría agregados a esta causa si bien significan un aporte valioso en relación con el fondo del problema planteado en el recurso, esto es, la legalidad o ilegalidad con que se habría tomado el acuerdo que dio origen a las sociedades en cuestión, es lo cierto que tal problema escapa al objeto de la protección solicitada, tal como se dijo anteriormente; además, tales dictámenes no obligan a este Tribunal y a lo sumo podrian ser considerados como antecedentes ilustrativos en relación con la cuestión que nos preocupa". 
resolución pronunciada por un juez competente, pero contrariando una disposición legal, puede y debe ser enmendada por la autoridad superior, asi un dictamen de la Contraloría por la autoridad judicial competente, en este caso la Corte de Apelaciones respectiva" 37.

En el mismo sentido y de manera categórica, ese Tribunal de Justicia ha declarado respecto de la Contraloría General de la República que "el articulo 20 de la Constitución es claro para incluir como tal a todo aquel que sea autor de un acto $u$ omisión ilegal y arbitrario que provoque amenaza, perturbación o privación del legitimo ejercicio de los derechos que señala, de tal manera que, al no estar expresamente excluido el Organismo Contralor, no debe existir duda en cuanto a que puede ser sujeto pasivo de este recurso"38.

En ese mismo sentido, la Corte Suprema, ha sentenciado que los dictámenes de la Contraloría General de la República obligan a la Administración; por ello, al afectado no le cabe ya actuar ante la autoridad administrativa contra tal pronunciamiento, sino ante los órganos jurisdiccionales por medio de las acciones procesales pertinentes. Y si se trata de derechos fundamentales reconocidos por la Constitución, será apto el recurso de protección, sin perjuicio de que queda siempre a salvo la posibilidad de recurrir a otras acciones que establezcan las leyes, desde que el recurso referido constituye solo un medio para que la acción de la justicia sea más operante y eficaz ${ }^{39}$.

La misma doctrina continúa confirmando invariablemente el máximo tribunal de justicia, al disponer que "un dictamen de la Contraloría General de la República puede ser corregido por la autoridad judicial competente, en la especie, por la vía del recurso de protección" 40.

\footnotetext{
C. A. Santiago, 16.01. 1989, Rol 427/88.

C. A. Santiago, 13.09.1989

C. S., 3.10.1989, RDJ 86, sec. 5, p. 186.

C. S., 5.11.1990, G.J. 129. p. 111. Se indica en la referida sentencia que: "Que del referido sentido y tenor literal del artículo 20 de la Constitución Política de la República, así como de la historia fidedigna de su establecimiento, resulta inconcuso que el recurso de protección-con arreglo al indudable sentido y alcance que impone la interpretación de su contenido literal- tiene por finalidad precisamente asegurar que cada uno y todos los funcionarios y las autoridades, individuales o colegiados, del Estado -sin distinción de nivel, jerarquía y naturaleza alguna- y cada persona o grupo de personas particulares, en el ejercicio de sus facultades y derechos -constitucionales, legales o reglamentarios- se encuadren en sus actos $u$ omisiones al imperio del derecho en lo concerniente al ejercicio de los derechos y garantías establecidos en los citados números del artículo 19 antes mencionado, de manera tal que con ellos ninguna persona o autoridad, en sus manifestaciones de voluntad o en su dejar de hacer respecto de ellos, cause a otro privación, perturbación o amenaza en el legitimo ejercicio de esos derechos y garantias. En la jurisprudencia, los Tribunales Superiores han declarado admisible recursos de protección interpuestos de conformidad con el artículo 20 de la Constitución Politica, en contra de actos de Ministros de Estados, de jefes de servicios nacionales, regionales o provinciales, de la Administración descentralizada, tanto de servicios o instituciones semifiscales, de empresas estatales o municipales; o de organismos autónomos, como las universidades o las municipalidades". Al efecto Soto Kloss ha precisado que la acción puede dirigirse contra "persona natural o jurídica, particular o autoridad, cualquiera sea ésta, si la administración, el juez, el legislador o el Contralor (Sото, Eduardo (1982), p. 309)".
} 
En otra sentencia de la Corte de Apelaciones, en su parte resolutiva manifiesta que corresponde a los Tribunales de Justicia conocer de las disputas entre partes y de acuerdo a lo consagrado en el art. 4 o del Código Orgánico de Tribunales el conocimiento de todos aquellos asuntos judiciales que se promuevan en el orden temporal dentro del territorio de la República cualquiera que sea la naturaleza o calidad de las personas que intervengan con excepción de la Contraloria General respecto de los juicios de cuentas ${ }^{41}$.

En otro caso, la Corte de Apelaciones, conociendo de un recurso de protección interpuesto por un particular afectado en una licitación pública por infringir la Contraloría General de la República las Bases de la Licitación mediante pronunciamiento hecho en un determinado dictamen, aquel Tribunal resolvió que si bien reconoce que las normas constitucionales y legales le otorgan una competencia y "funciones primordiales" de velar por el control de juridicidad de los actos de la Administración, sin embargo, sobre la base del principio de jurisdicción y el propio artículo 73 de la Constitución Política, "el proceder expuesto en el recurso no puede ni ha de substraerse de manera alguna a ese control superior que de todos los asuntos temporales y por mandato de la Constitución corresponde exclusivamente y privativamente a los tribunales de justicia, si el examen de la situación particular de que se trate lo haga exigible de modo manifiesto..." ${ }^{42}$. La doctrina nacional también ha estado de acuerdo en esta posición ${ }^{43}$.

C. A. Santiago, 2.08.1990, Rol 177-90, confirmada por sentencia de 5 de noviembre de 1990 de la Corte Suprema. En dicha sentencia se precisa "Que el recurso de protección contempla el artículo 20 de la Constitución Politica del Estado ampara al que por causa de acto u omisiones arbitrarios o ilegales sufre privación, perturbación o amenaza en el legítimo ejercicio de los derechos establecidos en los números que indica su art. 19, disposición amplia que faculta a cualquier persona, para interponer el recurso ante la Corte de Apelaciones contra actos u omisiones también de cualquier persona natural o jurídica, lo que concuerda con el principio general de que compete a los Tribunales de Justicia conocer de las disputas entre partes y consagrado en el art. $4^{\circ}$ del Código Orgánico de Tribunales al disponer que corresponde a dichos Tribunales el conocimiento de todos aquellos asuntos judiciales que se promuevan en el orden temporal dentro del territorio de la República cualquiera que sea la naturaleza o calidad de las personas que intervengan con la sola salvedad respecto de la Contraloría General de la República de las causas de cuentas que le corresponde conocer". Concluyéndose que por lo anterior "un Dictamen de la Contraloría General de la República puede ser corregido por la autoridad judicial competente, o sea, en este caso, por la Corte de Apelaciones de Santiago" C. A. Santiago, 28.05.1996, Rol 1.175/96.

43 En efecto, según lo afirmado por dos destacados juristas chilenos, en el ámbito del derecho constitucional y el derecho administrativo "de la letra, el origen y la historia del su establecimiento, se desprende claramente que el recurso de protección regulado en el citado artículo 20 de la Constitución Política puede impetrarse contra todo acto u omisión ilegal o arbitrario que cause amenaza, perturbación o privación de algunos de los derechos cautelados, quien quiera sea su autor. La disposición es amplísima en este sentido y la Contraloría General de la República no está excluida como eventual sujeto pasivo de dicho recurso. Un dictamen de la Contraloría General de la República, en cuanto puede declarar o negar derechos con efectos directos y lesivos para terceros, dada su condición de vinculante para la Administración del Estado, es impugnable jurisdiccionalmente; y constituye indudablemente, en ese caso, aún si le negare su carácter de decisión, una amenaza cierta de lesión de derechos, de los que puede reclamarse por vía del recurso de protección" (Silva, Alejandro 
Por otro lado, un dictamen pronunciado por la CGR, en el ejercicio de sus atribuciones legales y en materia de su competencia, no se estimó como una actuación ilegal o arbitraria, desde que le corresponde a dicho órgano contralor "verificar el examen de legalidad y constitucionalidad de los actos de la administración", de modo que "lo que ha hecho el órgano contralor es precisamente ejercer su potestad de fiscalización" 44 .

Del mismo modo, se consideró que no puede ser catalogado como ilegal un dictamen que obliga a recurrente a devolver dinero percibido a título de remuneración, desde que "el órgano contralor obró dentro de sus facultades constitucionales y legales". Sin embargo, se calificó como arbitraria la conducta de la recurrida y atentatoria del derecho de propiedad toda vez que "ha afectado su derecho de dominio sobre la asignación profesional que con efecto retroactivo Gendarmería le ha pagado" 45 . En otras palabras, si ya se habían cumplido las condiciones legales para recibir la asignación, se consideró injusto el exigir que se devuelva lo percibido con anterioridad al dictamen de Contraloría que reconoce el derecho.

\section{3.) LimitaCiONeS eStableCidAS A LA PROCEDENCIA DE LA PROTEC- CIÓN EN LA ÚLTIMA JURISPRUDENCIA}

Reciente jurisprudencia de la Corte Suprema ha establecido limitaciones en cuanto a la procedencia del recurso de protección. Así, por ejemplo, se ha estimado que no sería la vía para discutir acerca de la interpretación de las normas administrativas, lo que sería propio de acciones de lato conocimiento ${ }^{46}$.

Igualmente, en cuanto al plazo para interponerse, se ha sentenciado que no se suspende por la interposición de acciones administrativas ${ }^{47}$.

y Daniel, Manuel (1988), "Informe en derecho sobre La Procedencia de un Recurso de Protección en contra de la Contraloría General de la República", TD, 1988, pp. 100 y 101).

44 C.A. de Santiago, Rol 8317/2005, confirmado por la CS en Rol No 2199/2006

45 C.A. de Santiago, Rol 6552/2006, confirmado por la CS en Rol No 770/2007

46 Así, se ha sentenciado que "el medio idóneo para dilucidar cuestiones jurídicas acerca de la correcta interpretación y alcance que debe darse a normas jurídicas, como es el que se presenta en este caso, es el correspondiente a un juicio de lato conocimiento que permita resolver en propiedad acerca de la pretensión del recurrente". Y ello, en atención a "la naturaleza y finalidad del recurso de protección", al tratarse de "una vía urgente, eficaz y extraordinaria, destinada a reparar situaciones de hecho ilegales o arbitrarias que afecten un derecho constitucional no discutido" (C.S., 17.03.2010, Rol 1694/10).

47 Por tanto: "ninguno de los recursos deducidos por el actor-reconsideración y reclamo de ilegalidadhan tenido la virtud de suspender el plazo para el ejercicio de la acción constitucional, por cuanto como esta Corte lo ha expresado en anteriores fallos, el recurso de protección resulta totalmente compatible con el ejercicio de cualquiera otra acción, jurisdiccional o administrativa, dirigida a enervar los efectos nocivos de un acto ilegal o arbitrario, desde que el artículo 20 de la Carta Fundamental es preciso en declarar que esta acción es sin perjuicio de otros derechos" (C.S., 28.04.2010, Rol 1949/10). 
En cuanto al control de legalidad, se ha señalado por cierta jurisprudencia que dicho control sería más bien de carácter formal ${ }^{48}$ o solo si no ha actuado dentro de su competencia ${ }^{49}$. De forma tal que no le corresponde actuar como órgano contencioso administrativo, lo que es propio de la competencia de los tribunales de justicia ${ }^{50}$. Igualmente, no sería la vía para situaciones en que los derechos no sean indubitados ${ }^{51}$.

Dicha jurisprudencia -más reciente- de algún modo pone en duda la tesis finalista del órgano contralor, particularmente frente a peticiones de

Así se expresa que "El parecer de esta Corte es que el control de legalidad de los actos de la administración que la Contraloría está autorizada a realizar es de carácter meramente formal, sin que se estime pertinente que, ejerciendo dicho control, pueda revisar la jerarquización de los fines de las normas y procedimientos sometidos a su dictamen, pues dicha tarea es propia del legislador y de la misma administración, en el ejercicio de sus funciones de gobierno, pero a través de las entidades especializadas en cada área del quehacer público. En último término, frente a posiciones discordantes entre partes, son los tribunales de la República, esto es, los órganos jurisdiccionales, los llamados naturalmente a intervenir y resolver cada caso. No parece adecuado pensar que el órgano contralor pueda entrar a calificar la legalidad de fondo de todos los asuntos que pasan por su revisión, pues ello lo transformaría en un supra organismo que tendría siempre la última decisión sobre cualquier materia vinculada al derecho público, aun cuando estuvieren involucrados intereses de particulares" (C.A. de Santiago, Rol 5711/2006, c. 11, confirmado por la CS en Rol No 2008/2007).

49 Por ello, se desecha una acción dado que "tampoco se avizora un proceder arbitrario o ilegal de parte de la Contraloría General de la República, ente recurrido, pues ésta, al expedir el dictamen u oficio recurrido, y que lo hizo precisamente a requerimiento del mismo recurrente, ha obrado dentro del ámbito de sus atribuciones, que le entregan su ley orgánica, $N^{o} 10.336$, en concordancia con el artículo 98 de la CPR" (C.S., 3.11.2010, Rol 7647/10).

50 En suma, "la Contraloría no constituye un ente que pueda tener intervención y facultad de decidir en lo contencioso administrativo, pues dicha materia, en ausencia de tribunales especializados, que serían los llamados especial y naturalmente a conocer de este tipo de asuntos, queda en manos de los Tribunales ordinarios de justicia, lo cual se realiza en la práctica bajo la forma de diversos procedimientos: por ejemplo el juicio ordinario para el caso de ejercerse la acción de nulidad de derecho público, o bajo la forma de los diversos reclamos de ilegalidad establecidos en también diversas leyes y que abarcan, igualmente, variados aspectos, o en fin, a través de las también diversas reclamaciones administrativas de que disponen los particulares, todo lo cual no es del caso detallar con mayor profundidad, pues lo dicho tiende simplemente a dejar sentado que la Contraloría General de la República no constituye un órgano jurisdiccional que pueda resolver materias que afectan a intereses ya consolidados de particulares o empresas". Por lo mismo, la acción constitucional "no constituye una instancia de declaración de derechos sino que de protección de aquellos que, siendo preexistentes $e$ indubitados, se encuentren afectados por alguna acción u omisión ilegal o arbitraria y por ende en situación de ser amparados". (C.S., 19.08.2010, Rol 4759/10. En el mismo sentido, CS, 4.08.2011, Rol 6064/11)

51 Por lo mismo, "el recurso de protección constituye un arbitrio constitucional destinado a proteger el ejercicio de derechos que se encuentran indubitados, esto es, no discutidos, sin que esta vía constituya una instancia de declaración de los mismos. En esta perspectiva, la existencia de una controversia en cuanto a la procedencia de incluir el incremento del valor hora en la base de cálculo del bono de excedentes y acerca de si el bono que no ha sido pagado oportunamente devenga intereses y puede ser reajustado, impide estimar que los recurrentes y las personas a cuyo favor se recurre posean un derecho indubitado que los habilite para reclamar por la presente vía cautelar". (CS, 5.05.2010, Rol N ${ }^{\circ}$ 1063/10). De igual forma, "la discusión de los derechos que en definitiva pueden corresponder a las personas a cuyo favor se recurre debe ser materia del procedimiento pertinente, incoado mediante el ejercicio de las acciones respectivas, porque esta acción es simplemente cautelar de derechos preestablecidos, cual no es el caso" (CS, 30.12.2011, Rol 11.225/11). 
terceros, en cuanto ello pueda importar ejercicio de facultades propias de los tribunales ${ }^{52}$. Ello ha sido reiterado en otros fallos ${ }^{53}$.

En todo caso, como lo ha señalado la Corte Suprema, en una sentencia pronunciada en estos días, la CGR "en su actuación debe respetar la Constitución y la ley y se encuentra sometida al principio de legalidad, correspondiendo a los tribunales de justicia verificar y ejercer el control jurisdiccional de sus actos a través de las acciones contencioso administrativas que se interpongan". Incluso, hace presente que el órgano contralor "debe inclinarse frente a la jurisprudencia de los tribunales, lo que es fundamental para el orden institucional y particularmente válido cuando ésta es uniforme y permanente en el tiempo" por cuanto la jurisprudencia, "con mucho mayor énfasis que en otras ramas del derecho, es fuente del derecho administrativo", integrando así el denominado "bloque de la legalidad, siendo obligatoria para el ente contralor" 54 .

De esta forma, como también lo ha puntualizado la misma Corte $\mathrm{Su}$ prema, en principio, no puede quedar excluida la Contraloría del recurso de protección ${ }^{55}$. En tal sentido, distingue el tribunal superior, entre: a)

52 Se agrega "Que un parecer contrario al expresado conduciria a un estado de incerteza jurídica, con fuerte impacto en lo económico, puesto que siempre estaria latente la posibilidad de que, frente a determinada actuación de algún instituto u órgano de la administración del Estado, cualquier persona que se sintiere afectada o que incluso invocara derechos genéricos, podría recurrir a la Contraloría General de la República, la que tendría la última palabra en todos los casos en que interviniere, como ya se adelantó, y por razones no solo de forma, sino que también sustantivas, de tal suerte que los particulares nunca tendrian la posibilidad de concretar asuntos o negocios cuya autorización dependa de alguna autoridad administrativa, en tanto dicha entidad de control no se pronunciare sobre cada uno de tales asuntos. Ello incluso podría obligar a quienes quisieren hacer uso de algún beneficio o autorización concedida por cualquier entidad administrativa a indagar, de modo previo a la concreción de cualquier obra o negocio, el parecer del órgano contralor, lo cual no parece pertinente, porque ello importaría extender el control burocrático de dicha institución a niveles jurídicamente insoportables". Se concluye "Que, lo anteriormente indicado, además, se llevaría a cabo mediante la utilización de procedimientos, por parte de la entidad recurrida, que no se avienen con la correcta defensa de los intereses que cada uno de los involucrados en el asunto de que se trate pueda llevar a cabo. Es así como en este sentido, se advierte que la actividad fiscalizadora que ha llevado a cabo la Contraloría en el caso que se analiza, viene a constituir una suerte de sustituto de la actividad jurisdiccional, sede esta última en la que naturalmente se deben resolver conflictos entre partes, como se dijo anteriormente. Aceptar el criterio que esta Corte rechaza importaria que la normativa de fondo y los procedimientos pertinentes quedarían expuestos a una constante relativización, lo cual resulta incompatible con una actividad regulatoria, ya que la existencia de tales procedimientos garantiza que las decisiones de la autoridad se adopten con la transparencia y publicidad que requieren las actuaciones administrativas, particularmente cuando, como en el presente caso, han de tener impacto económico. En suma, este Tribunal no comparte la tesis finalista, en virtud de la cual el órgano contralor de la República ha emitido un juicio sobre el fondo del asunto, puesto que, reconociendo que tiene facultades para pronunciarse sobre consultas de particulares, no puede realizar una acción invasiva de las atribuciones de otros órganos de la administración del Estado". (C.A. de Santiago, Rol 5711/2006, c. 11, confirmado por la CS en Rol No 2008/2007).

53 En el mismo sentido véanse sentencias de C.S. 27.07.2006, Rol 2224/06; 2.10.2006, Rol 4617/06 y 5.10.2006, Rol 4614/06.

$54 \quad$ CS, 3.07.2012, Rol 2791/12

55 CS, 12.01.2012, Rol 10499/01. En efecto, afirma la Corte que, a través del tiempo, se han interpuesto recursos de protección en contra de las siguientes actuaciones de la 
dictámenes constitutivos de "decisiones", que son verdaderos actos terminales; b) aquellos que "pueden dar lugar a actos administrativos posteriores", que constituyen actos de trámite; y c) "dictámenes que no son creadores de derecho" y que tienen por objeto instruir a la Administración respecto al alcance o interpretación que debe darse a algún precepto legal, el que no cabe dentro de la definición de acto administrativo, siendo equivalentes a verdaderas circulares ${ }^{56}$.

\section{3) CONCLUSIONES}

De lo seńalado puede concluirse que:

1. La toma de razón de los actos administrativos, que importa el control preventivo de sujeción de los mismos a la Constitución y a la ley, tiene fundamento constitucional. Dicha actuación es concreción del los principios de supremacía constitucional y de legalidad.

2. El TC, en diversos pronunciamientos ha señalado que no puede el legislador eximir del control de legalidad a los actos de la administración, puesto que dichas atribuciones tienen fundamento constitucional.

3. Existe controversia en cuanto a la posibilidad de impugnar judicialmente la actuación de toma de razón, en particular a través del recurso de protección. De hecho, en la década de los noventa se presentaron contiendas de competencias que el Senado resolvió a favor de la CGR. En últimos fallos, los tribunales superiores de justicia han señalado la improcedencia de dicha vía constitucional.

4. Por su parte, la potestad dictaminante de la CGR encuentra su fundamento en la propia Carta Fundamental (arts. 98 y 99), en el derecho de petición y en los artículos 6, 9 y 19 de la Ley Orgánica de la Contraloría. Dichos dictámenes son obligatorios para los funcionarios públicos y no resultan procedentes tratándose de asuntos litigiosos y en aquellos que se encuentran sometidos al conocimiento de los tribunales de justicia.

5. Dichos actos dictaminantes pueden ser impugnados a través del recurso de protección, particularmente en tanto importe intromisión en las facultades privativas de los tribunales de justicia o si no se ha actuado dentro de la esfera propia de su competencia. En tal sentido, la Corte Suprema ha precisado que la jurisprudencia es fuente del Derecho Administrativo, integrando el denominado "bloque de legalidad".

Contraloría General de la República: dictámenes, resoluciones recaídas en sumarios administrativos sustanciados por órganos de la Administración o por la propia Contraloría, para obtener que se tome razón de un acto o cuestionando la toma de razón realizada, y por último del trámite de registro, existiendo muy pocos casos que se refieran a otras materias. 